\title{
Structural, Thermal and Magnetic Characterization of Ni-Mn-Ga Ferromagnetic Shape Memory Alloys
}

\author{
R. Jesintha Rani ${ }^{1,2}$, R. Senthur Pandi ${ }^{1}$, S. Seenithurai ${ }^{1}$, S. Vinodh Kumar ${ }^{1}$, \\ M. Muthuraman ${ }^{1}$, M. Mahendran ${ }^{1, *}$ \\ ${ }^{1}$ Smart Materials Lab, Department of Physics, Thiagarajar College of Engineering, Madurai, 625015, India
${ }^{2}$ Department of Physics, Namakkal Kavignar Ramalingam Government Arts College for Women, Namakkal, 637001, India
}

\begin{abstract}
Ni-Mn-Ga Ferromagnetic Shape Memory Alloys (FSMA) are highly interested in industrial actuators and energy harvesters because of its uniqueness in microstructure and multiple phases of these materials at different temperatures. The type of crystal structure, lattice parameters and magnetic properties depend on the alloy composition. The transformation and crystallographic properties are usually mapped to average number of valence electrons per atom. The present work deals with the fundamental characterization of single crystal and polycrystalline nature of these alloys. Though, the polycrystal shows low magnetic field induced stain (MFIS), the easy preparation techniques and cost effective aspects compared with the single crystals makes an impressive interest in dealing with that. The structural, thermal and magnetic parameters are observed and compared for these single and polycrystals.
\end{abstract}

Keywords Ni-Mn-Ga Polycrystals, Smart Materials, Magnetic Properties, Phase Transformations, Magnetic Field Induced Stain, Sensors And Actuators

\section{Introduction}

Ferromagnetic Shape Memory Alloys (FSMAs) are a new class of active materials that have generated considerable interest among the scientific community. They are next generation to Shape Memory Alloys (SMAs), and they share many common properties with SMAs. Conventional SMAs are slow, especially in cooling, thus limiting their efficiency in applications. On the other hand, FSMAs show larger Magnetic Field-Induced Strain (MFIS) with quick response at low frequencies than the other active materials such as piezoelectric and magnetostrictive materials[1].

Two alloy systems have predominantly demonstrated field-induced strain, 0.5\%[2] in Fe-Pd and 6-10\%[3-7] in Ni-Mn-Ga. Ni-Mn-Ga FSMA is focused among the different types of active materials because of their large field induced strain[8,9]. They show upto $10 \%$ strain response to an applied magnetic field by the twin boundary motion present in the martensite phase[7]. This is the main advantage of the material; it would overcome the 'frequency bound' of the conventional SMAs.

Both the magnetic shape memory effect and the mechanical properties of single crystal Ni-Mn-Ga alloys vary significantly due to strong dependence on crystal structure,

* Corresponding author:

manickam-mahendran@tce.edu (M. Mahendran)

Published online at http://journal.sapub.org/ajcmp

Copyright (C) 2011 Scientific \& Academic Publishing. All Rights Reserved material composition, initial microstructure, and variant volume fraction[10-30]. Material composition plays a critical role in the determination of the martensite to austenite transformation temperatures. It has been observed in particular that the martensite start temperature of Ni-Mn-Ga is sensitive to composition[9,13,15]. For practical applications of Ni-Mn-Ga, it is necessary to use material compositions that place the austenite to martensite transformation temperature well above the expected operating temperature. This is important because the effects of martensite crystal structure, temperature and maximum strain capability are all interrelated.

Material composition must be considered as an important parameter for practical applications. The present work is tried to explain about the composition significance in structural, thermal and magnetic properties of these alloys in single crystal as well as polycrystal.

\section{Experimental Procedure}

\subsection{Single Crystal Preparation}

The single crystal used for this work is received from Prof. Robert C. O'Handley, MIT, USA. Usually the Ni-Mn-Ga single crystal is prepared by the Bridgman technique. High-purity nickel, manganese and gallium are arc melted into buttons and then drop cast into a chilled copper mould. As-cast ingots are placed in an alumina crucible and heated at $1350^{\circ} \mathrm{C}$ for one hour for homogenization. The crucible is 
then withdrawn from the hot zone at a minimum rate per hour. In order to reduce the evaporation of manganese during the crystal growth, the furnace is back-filled to a positive pressure of $6.8 \times 10^{5} \mathrm{~Pa}$ with purified argon gas after the chamber has been out gassed at $1350^{\circ} \mathrm{C}$ under vacuum. A piece is cut along the length from the crystal which is heat treated at $900^{\circ} \mathrm{C}$ for $24 \mathrm{hrs}$ in a purified argon atmosphere. The samples are wire-cutted for various characterizations.

\subsection{Polycrystal Preparation}

The polycrystalline ingots are produced using an arc-melting furnace. The arc melting furnace consists of a copper plate as hearth, which is maintained at room temperature by water circulation. The grooves in the plate are used as containers for melting the raw materials. A vacuum of up to $10^{-3} \mathrm{~m}$.bar is created inside the chamber and flushed with high pure argon gas before melting process. During melting, the chamber is completely filled with argon gas. The intensity of the arc for melting the samples can be reached by increasing the power to the Tungsten electrode.

The raw materials of $4 \mathrm{~N}$ purity are weighed in the stoichiometric ratio. The materials in the chunk and granules form are used for melting. As the powder sometimes flies out of the copper plate due to the force of arc, shifting the stoichiometry, the powder is made into granules for melting. After the first melt, all the ingots are reverted to their same place and melted again in the argon atmosphere. This melting procedure is repeated up to 6 times to ensure a good homogeneity in the sample.

After melting, the samples are sealed in quartz ampoules filled with argon atmosphere. Thermal treatment is carried out in a box furnace with $1100^{\circ} \mathrm{C}$ for 10 days for the phase transformation. The samples are kept in a furnace for a long time to form the required phase structure. Quenching process is done to stabilize the phase. Table 1 shows the different compositions of Ni-Mn-Ga single and polycrystals.

Table 1. Nominal compositions (at \%) of the Ni-Mn-Ga FSMA alloys used in this work for the characterization studies

\begin{tabular}{|c|c|c|c|}
\hline Sample Name & $\mathrm{Ni}$ & $\mathrm{Mn}$ & $\mathrm{Ga}$ \\
\hline Single Crystal1 & 48.3 & 33.1 & 18.6 \\
\hline Single Crystal 2 & 48.2 & 31.7 & 20.1 \\
\hline Polycrystal 1 & 50 & 25 & 25 \\
\hline Polycrystal 2 & 48 & 26 & 26 \\
\hline
\end{tabular}

\section{Characterization of Ni-Mn-Ga Alloys}

\subsection{Structural Studies}

X-Ray Diffraction (XRD) pattern is used to study the structure of the prepared samples. The samples are crushed into powders. Then the crushed Ni-Mn-Ga powders are annealed in an inert atmosphere at $500-700^{\circ} \mathrm{C}$ for 3 hours to remove the residual stresses imparted during the crushing of the samples. The powder X-ray diffraction data are collected at room temperature using an $18 \mathrm{~kW}$ copper rotating anode-based powder diffractometer fitted with a graphite monochromator in the diffracted beam. The data collection in the $2 \theta$ range of $10-80^{\circ}$ is carried out using scintillation counter with the scan rate of $2 \%$ min. Figure $1 \& 2$ shows the XRD pattern for Ni-Mn-Ga single crystals.

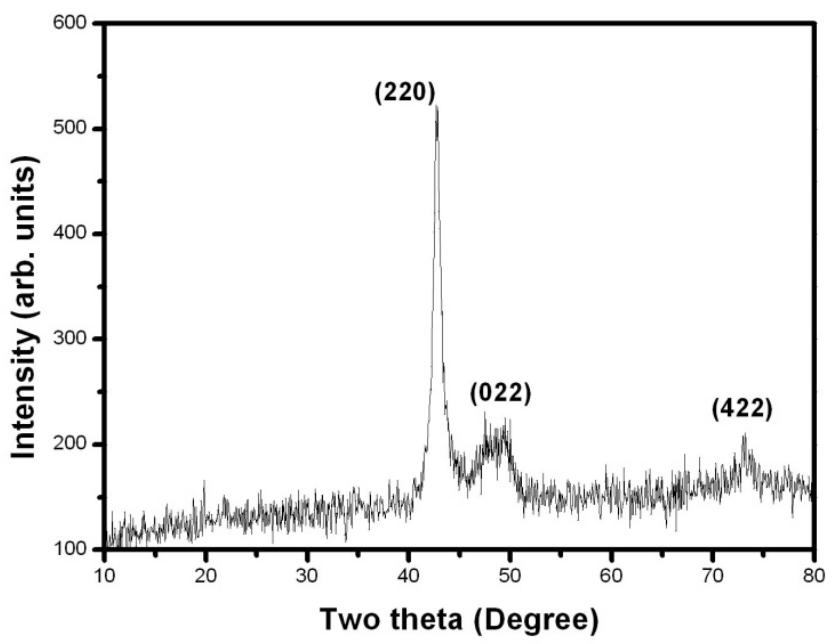

Figure 1. X-ray diffraction pattern of the single crystal 1. The reflectiopeaks are indexed in the figure

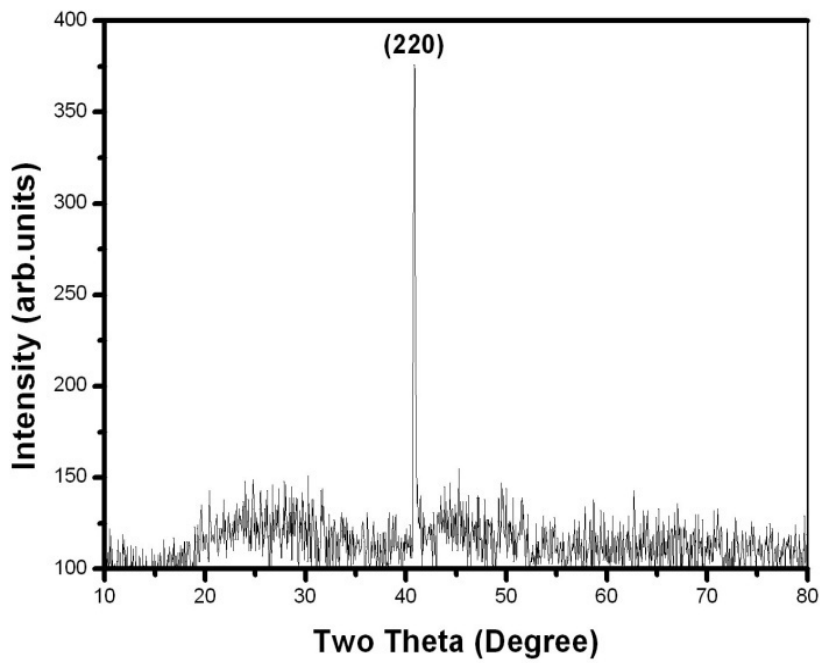

Figure 2. X-ray diffraction pattern of the single crystal 2. The observed dominant peak is indexed as (220)

The characteristic reflections are indexed by comparing with the reported literatures[16,18]. The (220), (022), (422) reflection peaks are identified in single crystal 1 . The structure of the crystals is identified as tetragonal one. The lattice parameters of the single crystal 1 and single crystal 2 are $\mathrm{a}=$ $\mathrm{b}=0.5932 \mathrm{~nm}, \mathrm{c}=0.5606 \mathrm{~nm}, \mathrm{a}=\mathrm{b}=0.5941$ and $\mathrm{c}=$ $0.5618 \mathrm{~nm}$ respectively. It confirms that the material is martensite at room temperature. A slight change in composition does not affect the crystal structure of the material but the cell volume drastically increases. The atomic radius of $\mathrm{Ni}$, $\mathrm{Mn}$ and $\mathrm{Ga}$ are $0.125 \mathrm{~nm}, 0.127 \mathrm{~nm}$ and $0.141 \mathrm{~nm}$ respectively. The cell volume increases when $\mathrm{Mn}$ atom replaces $\mathrm{Ni}$ and $\mathrm{Ga}$ replaces $\mathrm{Ni}$ and $\mathrm{Mn}$ as the size of the atom is high. The cell volume decreases when $\mathrm{Ni}$ atom replaces $\mathrm{Mn}$ and $\mathrm{Ga}$. The dominant single peak in the diffraction spectra shows the 
single crystal nature of the samples. Figure 3 and 4 show the $\mathrm{X}$-ray diffraction pattern of Ni-Mn-Ga polycrystals.
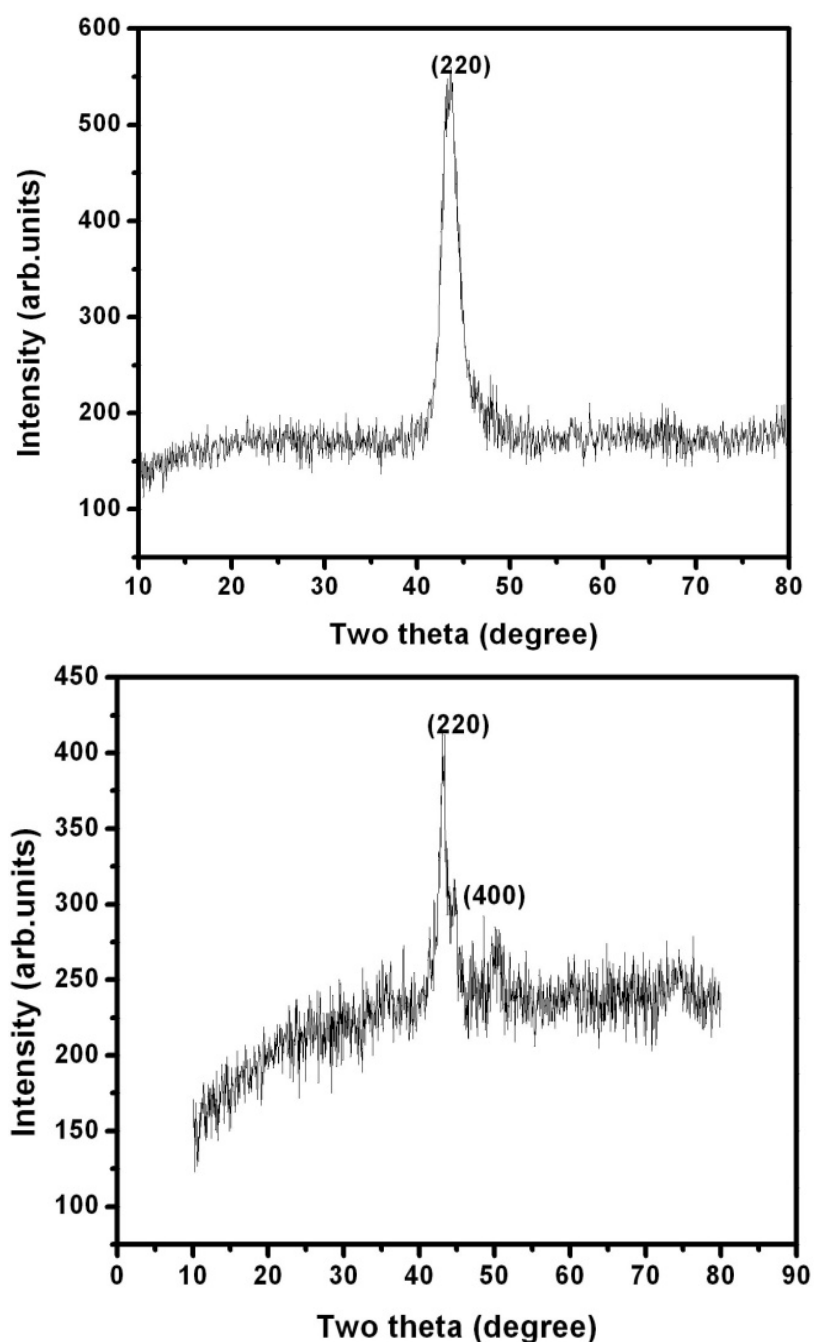

Figure $3 \& 4$. X-ray diffraction pattern of the polycrystal 1 and 2 respectively. The The reflection peaks are indexed in the figure

The dominant peaks confirm the Ni-Mn-Ga alloy. The two different compositions show their dominant peaks in same angle. But their intensities are different. A stoichiometric polycrystal 1 alloy has cubic, Heusler type crystal structure $[31,32]$ with lattice parameter $\mathrm{a}=\mathrm{b}=\mathrm{c}=0.5828 \mathrm{~nm}$ at room temperature. In polycrystal 1, (400) peak is also observed which is the reflection of the cubic phase of the alloy[18,19]. Since the reflection peaks for the tetragonal or orthorhombic phase is not observed from the diffraction pattern, it is identified that both polycrystal samples are in cubic phase at room temperature. The lattice parameter for the polycrystal 2 is $\mathrm{a}=\mathrm{b}=\mathrm{c}=0.586 \mathrm{~nm}$.

In general, the peak occurred at lower angles with the (200) reflection peak exhibits the orderdered structure of the crystal. We have not observed the (200) peak in our samples. The (220) peak observed here reflects the $\mathrm{L} 2_{1}$ structure in the samples. The (220) reflection peak does not show any peak splitting.

Usually the peak splitting in the peak reflects the orthorhombic structure[20]. Though our samples exhibit the cubic structure with dominant (200) peak, we cannot observe any splitting in the figure. The splitting may occur in the martensite phase of the sample. Table 2 shows the lattice parameters and their unit cell volume of prepared Ni-Mn-Ga alloys.

Table 2. Lattice parameters of the crystals observed from the X-ray diffraction pattern studies

\begin{tabular}{|c|c|c|c|c|c|}
\hline \multirow[t]{2}{*}{ Composition } & \multicolumn{3}{|c|}{$\begin{array}{c}\text { Lattice parameters } \\
(\mathrm{nm})\end{array}$} & \multirow{2}{*}{$\begin{array}{l}\text { Unit-cell } \\
\text { volume } \\
\left(\mathrm{nm}^{3}\right)\end{array}$} & \multirow[t]{2}{*}{$\mathrm{c} / \mathrm{a}$} \\
\hline & $\mathrm{a}$ & $\mathrm{b}$ & $\mathrm{c}$ & & \\
\hline $\mathrm{Ni}_{48.3} \mathrm{Mn}_{33.1} \mathrm{Ga}_{18.6}$ & 0.5932 & -- & 0.5606 & 0.1973 & 0.9450 \\
\hline $\mathrm{Ni}_{48.2} \mathrm{Mn}_{31.7} \mathrm{Ga}_{20.1}$ & 0.5941 & -- & 0.5618 & 0.1983 & 0.9457 \\
\hline $\mathrm{Ni}_{50} \mathrm{Mn}_{25} \mathrm{Ga}_{25}$ & 0.5828 & -- & -- & 0.1980 & -- \\
\hline $\mathrm{Ni}_{48} \mathrm{Mn}_{26} \mathrm{Ga}_{26}$ & 0.5860 & -- & -- & 0.2012 & -- \\
\hline
\end{tabular}

\subsection{Thermal Studies}

Whenever the phase transformation occurs from martensite to austenite, energy is released or absorbed. This can be measured by Differential Scanning Calorimetry (DSC). The martensite transformation strongly depends on the composition. A small change in the composition may lead to a large shift in the transformation temperature. But the Curie temperature is less sensitive to the composition. Figure 5 is taken for the Ni-Mn-Ga single crystals. The graph is plotted between the heat flow and temperature. The graph shows first order (martensite) and second order (magnetic) transformation temperatures of the sample. In single crystal 1 , the martensite finish temperature $\left(\mathrm{M}_{\mathrm{f}}\right)$ starts in the temperature region of $308 \mathrm{~K}$. The peak has some fluctuations. These fluctuations may be due to the existence of allotropic transformation in the solid-state.

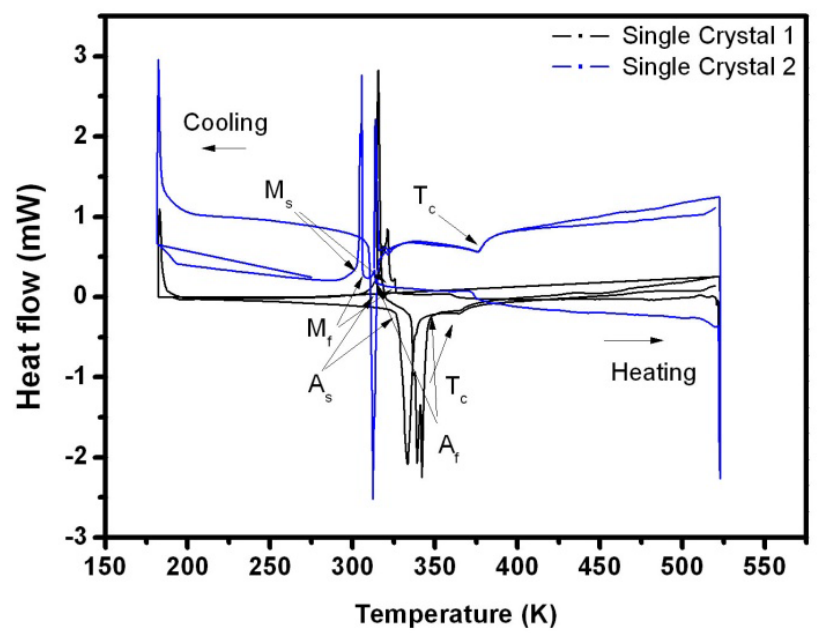

Figure 5. Thermal transformation studies of the Ni-Mn-Ga single crystals. The results are obtained from the DSC

The sharp peak in the cooling reveal the martensite temperatures such as martensite start $\left(\mathrm{M}_{\mathrm{s}}\right)$, and martensite finish $\left(\mathrm{M}_{\mathrm{f}}\right)$. Similarly sharp peak in the heating curve explains the austenite start $\left(\mathrm{A}_{\mathrm{s}}\right)$ and finish $\left(\mathrm{A}_{\mathrm{f}}\right)$ temperatures. This transformation studies are highly helpful to find out the martensite and austenite regions of the sample. The martensite phase ends at $325 \mathrm{~K}$ and austenite starts at $326 \mathrm{~K}$ ends at 341 $\mathrm{K}$. There is a small kink at $366 \mathrm{~K}$. It is due to the change of 
second order magnetic transition. This temperature is called as Curie temperature. The sharp transition in the curve reveals that the homogeneity is retained in the alloy and the result coincides with work of Richard et al[16]. In single crystal 2, the first order solid to solid transformation of the material occurs in the range temperature range between 299-316 K. The second order magnetic transformation occurs at $376 \mathrm{~K}$. Sharper peak in the transformation temperatures is expected because of their tetragonal structure in the martensite phase. Figure 6 shows the heating and cooling curve for the polycrystal 1 .

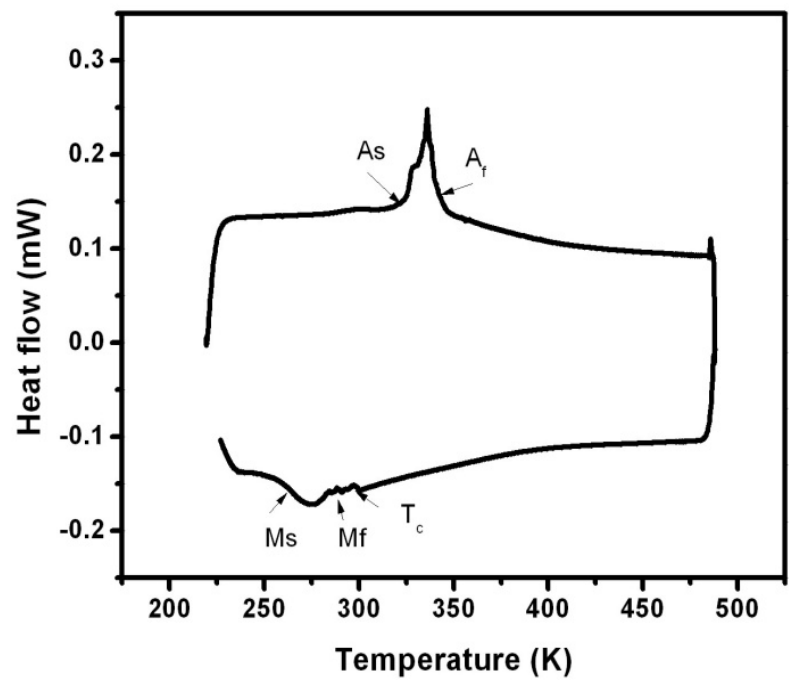

Figure 6. Thermal transformation studies of Ni-Mn-Ga polycrystal 1

The heating and cooling curves are obtained from the DSC Figure 7 and 8 heating and cooling of the polycrystal 2 is split for interpretation purpose. The martensite phase in these structures is observed at the low temperature range. In the case of polycrystal 2 it is extremely low.

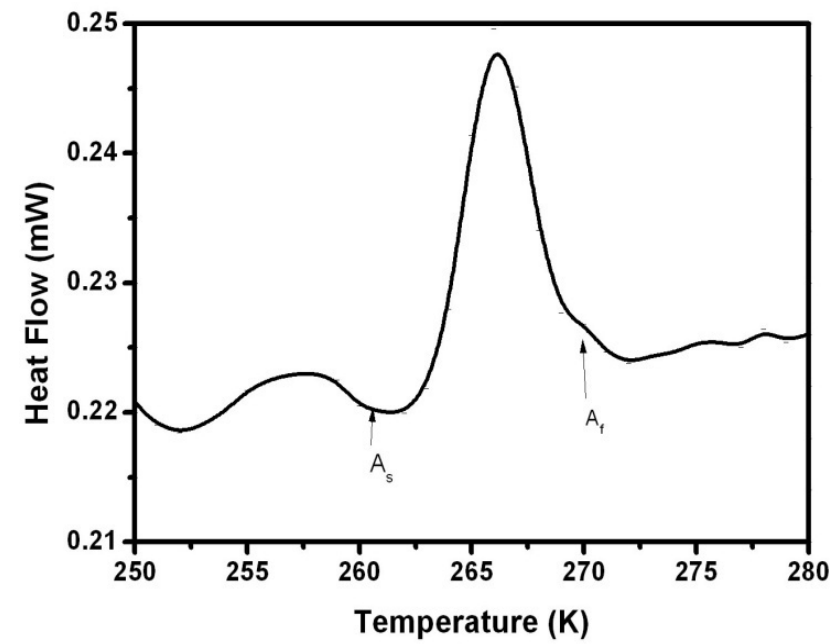

Figure 7. Thermal transformation of Polycrystal2 during the heating process

The composition of the crystals is a reason for their low temperature phase transformation. The transformation temperatures observed form the DSC measurements for the polycrystals and single crystals are tabulated in the Table 3 .
Table 3. Thermal transformation temperature of the Single Crystall (SC1), Single Crystal2 (SC2), Polycrystal1(PC1) and Polycrystal2 (PC2)

\begin{tabular}{|l|l|l|l|l|l|l|l|l|}
\hline \multirow{2}{*}{$\begin{array}{c}\text { Sam- } \\
\text { ple } \\
\text { Name }\end{array}$} & \multicolumn{5}{|c|}{$\begin{array}{c}\text { Transformation } \\
\text { Temperatures }(\mathrm{K})\end{array}$} & $\begin{array}{c}\text { Hyst } \\
\text { ere- } \\
\text { sis }\end{array}$ & $\begin{array}{c}\mathrm{T}_{\mathrm{o}} \\
\mathrm{K}\end{array}$ \\
\cline { 2 - 6 } $\mathrm{SC} 1$ & $\mathrm{M}_{\mathrm{f}}$ & $\mathrm{M}_{\mathrm{s}}$ & $\mathrm{A}_{\mathrm{s}}$ & $\mathrm{A}_{\mathrm{f}}$ & $\mathrm{T}_{\mathrm{c}}$ & & & \\
\hline $\mathrm{SC} 2$ & 299 & 325 & 326 & 341 & 366 & 7.70 & 11 & 310.5 \\
\hline PC1 & 267 & 272 & 309 & 316 & 376 & 7.64 & 16 & 333 \\
\hline PC2 & 183 & 217 & 260 & 270 & 345 & 7.40 & 53 & 243.5 \\
\hline
\end{tabular}

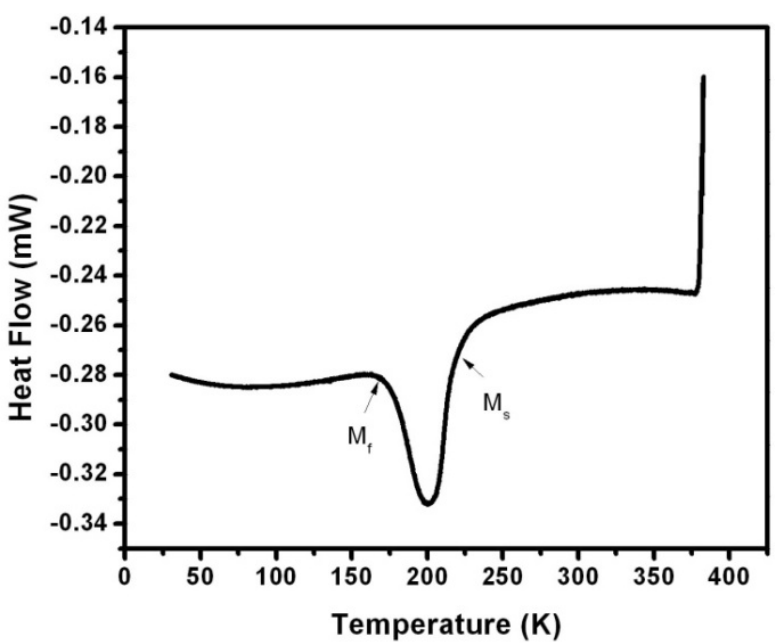

Figure 8. Thermal transformation studies of the Ni-Mn-Ga polycrystal 2. The result shows the cooling curve obtained from the DSC

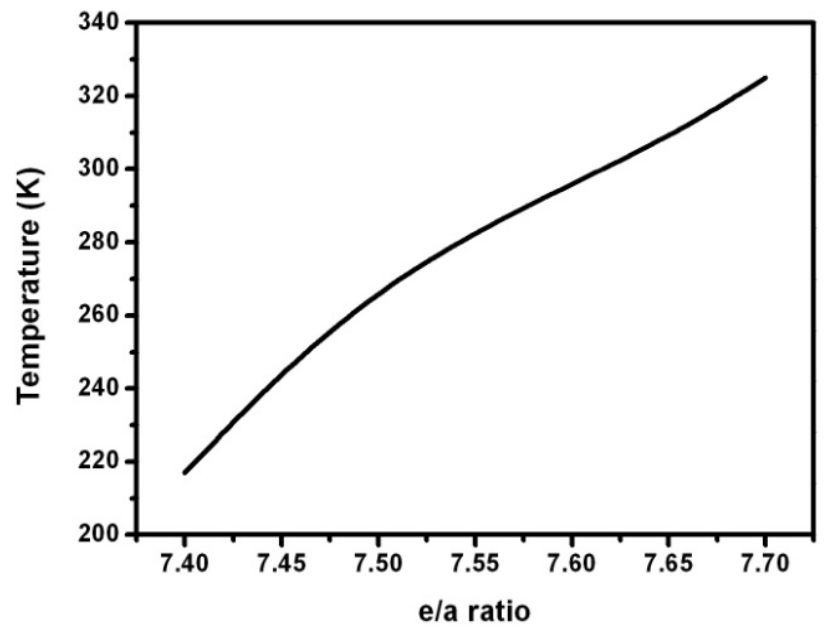

Figure 9. The thermal transformation temperature is correlated with the e/a ratio of the prepared compositions

Table 3 shows the transformation temperatures obtained from the DSC curve. The transformation temperature increased when $\mathrm{Mn}$ replaces $\mathrm{Ga}$ atom and it decreases when $\mathrm{Mn}$ atom replaces $\mathrm{Ni}$ atom. The obtained results coincide with Chernenko et al[9] and Wirth et al[21]. Kokorin et al[8] reported that the decrease in unit cell volume increases the transformation temperatures of the alloy. The results obtained in our work agree well with Kokorin et al's[8] work. The decrease in unit cell volume is confirmed from the diffraction studies.

The electron to atom ratio plays a vital role in determining the transformation temperatures. Jin et al (2002) found a relation between e/a and $T_{m}$ and it is expressed as 


$$
\mathrm{T}_{\mathrm{m}}=702.5(\mathrm{e} / \mathrm{a})-5067 \mathrm{~K}
$$

The transition temperature of the prepared alloys linearly increased with the e/a ratio of the compositions. It is in good agreement with the Jin et al's work[22].

\subsection{Magnetic Studies}

The magnetic characteristics of the single crystal and polycrystal alloys are studied through the Vibrating Sample Magnetometer (VSM). The isothermal magnetization as a function of field at room temperature is done for the alloys. The magnetic moment Vs Magnetization curve is plotted for the prepared alloys.

The magnetic studies of the single crystals are shown in figure 10. The saturation magnetization of the single crystal alloys is comparatively lower than the polycrystal. It is because of the tendency to align the domains in the field is comparatively good in the single crystals. The very low coercivity of the crystal should be useful for their actuator applications. The crystal structure of single crystals plays a vital role in determining the magnetic moment of the material. In the $\mathrm{L} 2{ }_{1}$ ordered structure, $\mathrm{Mn}$ atom possess a large magnetic moment of $3-4 \mu \mathrm{B}$.

In this structure, ferromagnetic coupling between two $\mathrm{Mn}$ atom is taking place when the Mn occupies the 'b' site with high atomic order. However, anti-ferromagnetic coupling will occur if the Mn atom occupy a wrong sites (usually Mn atom occpies d site) in an atomically disordered case. The magnetic parameters are tabulated in the Table 4 .

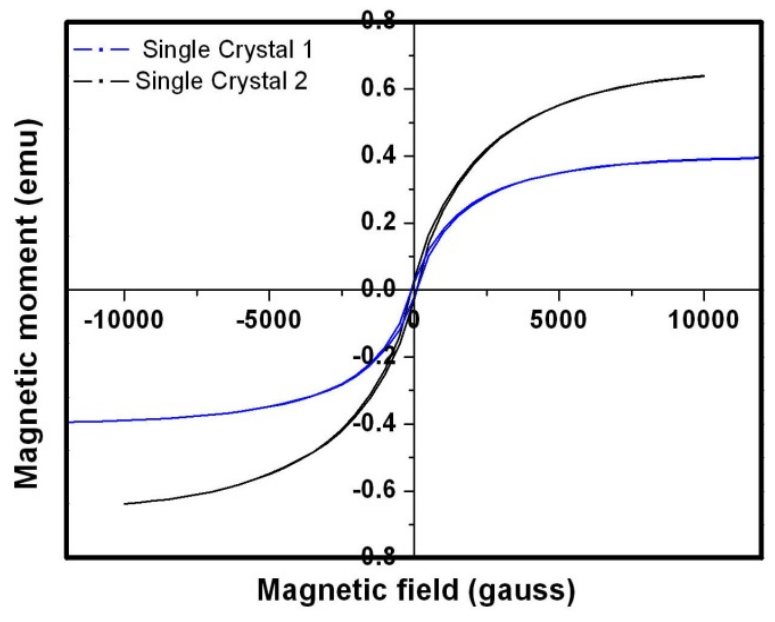

Figure 10. Magnetization curve for SC1 and SC2 recorded by VSM

Table 4. Magnetic Parameters of the Ni-Mn-Ga single and polycrystal alloys obtained from the VSM

\begin{tabular}{|c|c|c|c|c|}
\hline Sample Name & e/a & Remanance & Coercivity & $\mathrm{M}_{\mathrm{S}}$ \\
\hline SC1 & 7.70 & 0.0134 & 87.75 & 0.3893 \\
\hline SC2 & 7.64 & 0.0269 & 85.66 & 0.6340 \\
\hline PC1 & 7.50 & 0.0740 & 50.706 & 5.6034 \\
\hline PC2 & 7.40 & 0.2130 & 39.083 & 9.4893 \\
\hline
\end{tabular}

Ferromagnetic behavior is observed in figure 11 with steep rise at lower field and tendency to saturate at higher fields in the polycrystals. The in plane hysteresis loop of the samples exhibited a saturation field around 5000 G. In polycrystal 1 , the magnetic moment at the saturation mag- netization is around 5 emu which is lower than polycrystal 2. The saturation magnetization of the curve also depends on the composition of the structure. The interaction between the $\mathrm{Mn}$ atoms also plays an important factor in fixing the saturation magnetization of the alloys.

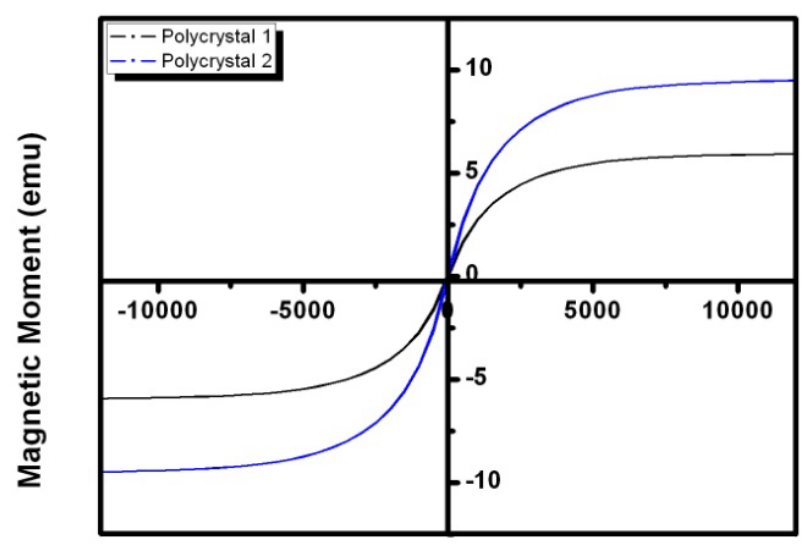

Magnetic field (Gauss)

Figure 11. Magnetization curve of $\mathrm{PC} 1$ and $\mathrm{PC} 2$ recorded by VSM

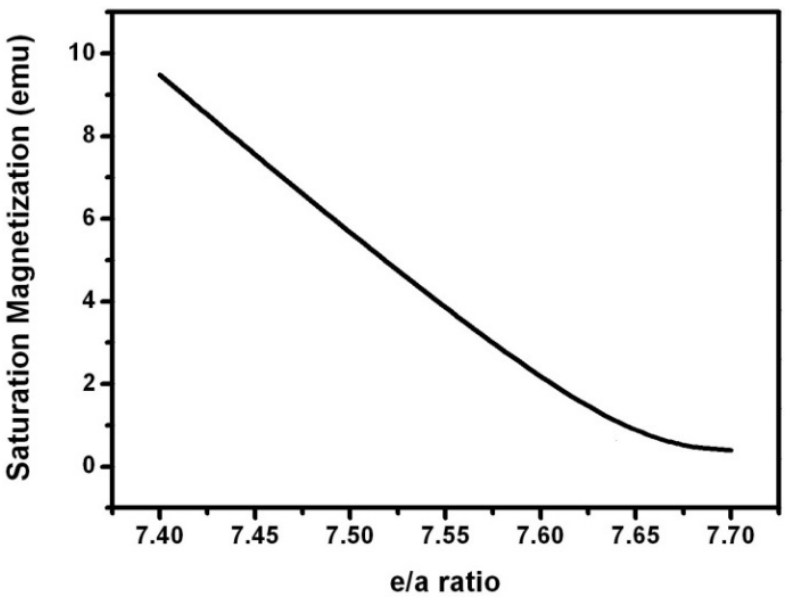

Figure 12. Magnetic saturation against the e/a ratio of the prepared alloys

The very small coercive field signifies the extremely soft ferromagnetic character of the sample. Figure 12 shows that the saturation magnetization of the prepared alloys decreases with the increasing e/a ratio of the compositions.

\section{Conclusions}

Structural, thermal and magnetic studies are carried out for Ni-Mn-Ga Single and Poly Crystals. The structural study confirms the presence of the martensite structure in the single crystal alloys and the austenite phase in the polycrystal alloys. The thermal measurements evidence the phases present in the alloys with their transformation temperatures. The room temperature martensite structure is confirmed and the transition temperature is calibrated through DSC data. The magnetic nature of the alloys is identified through VSM studies. The magnetic parameters such as saturation magnetization, coercivity and remanance are identified and analyzed with e/a ratio. The mechanical studies and ferro- 
magnetic shape memory effect of these crystals have to be studied in the near future.

\section{ACKNOWLEDGEMENTS}

MM thanks Dr. Robert C.O'Handley for introducing him to the subject. The authors acknowledges the UGC, New Delhi and UGC- DAE CSR, Indore for providing financial support.

\section{REFERENCES}

[1] Marioni, M. A., O’ Handley, R.C., and Allen, S.M., 2003, Pulsed magnetic field-induced actuation of Ni-Mn-Ga single crystals, Applied Physics Letters, 83, 3966-3968

[2] James, R. D., Tickle, R., and Wutig, M., 1999, Large field-induced strains in ferromagnetic shape memory materials, Materials Science and Engineering A, 273-275, 320-325

[3] Likhachev, A. A., and Ullakko, K., 2000, Magnetic-field-controlled twin boundaries motion and giant magneto-mechanical effects in Ni-Mn-Ga shape memory alloy, Physics Letter A, 275, 142-151

[4] Murray, S. J., Marioni, M., Allen, S. M., O’Handley, R. C., and Lograsso, A.T., 2000, 6\% magnetic-field-induced strain by twin-boundary motion in ferromagnetic Ni-Mn-Ga, Applied Physics Letters, 77, 886-888

[5] Heczko, O., Sozinov, A., and Ullakko, K., 2000, Giant field-induced reversible linear strain in magnetic shape memory NiMnGa at room temperature, IEEE Transactions on Magnetic, 36, 3266-3268

[6] Sozinov, A., Likhachev, A. A., Lanska, N., and Ullakko, K., 2002, Giant magnetic-field-induced strain in NiMnGa seven-layered martensitic phase, Applied Physics Letters, 80, 1746-1748

[7] Müllner, P., Chernenko, V. A., and Kostorz, G., 2004, Large cyclic magnetic-field-induced deformation in orthorhombic (14M) Ni-Mn-Ga martensite, Journal of Applied Physics, 95, 1531-1-6

[8] Kokorin, V. V., and Chernenko, V. A., 1989, Martensitic transformation in a ferromagnetic Heusler alloy, Physics of Metals and Metalography, 68, 111-115

[9] Chernenko, V. A., Amengual, A., Cesari, E., Kokorin, V. V., and Zasimchuk, I. K., 1995, Thermal and magnetic properties of stress-induced martensites in Ni-Mn-Ga alloys, Journal de Physique IV, 5 (C2), 95-98

[10] Chokkalingam, R., Senthur Pandi, R., Vallal Peruman, K., et al., 2010, Shape memory behavior of Ni-Mn-Ga ferromagnetic shape memory alloy, Proc. of ICPEFM, CP1313, 199-201

[11] Vallal Peruman, K., Mahendran, M., Seenithurai, S., Chokkalingam, R., Singh, R.K., and Chandrasekaran, V., 2010, Internal stress dependent structural transition in ferromagnetic $\mathrm{Ni}-\mathrm{Mn}-\mathrm{Ga}$ nanoparticles prepared by ball milling, Journal of Physic sand Chemistry of Solids, 71, 1540-1544
[12] Pushpanathan, K., Chokkalingam, R., Senthur Pandi, R., and Mahendran, M., 2011, Effect of annealing on transformation temperature and magnetization in the Ni-Mn-Ga alloy, Materials and Manufacturing Process, 26, 223-229

[13] Pons, J., Chernenko, V. A., Santamarta, R. and Cesari, E., 2000, Crystal structure of martensitic phases in Ni-Mn-Ga shape memory alloys, Acta Materialia, 48, 3027-3038

[14] Vallal Peruman, K., Chokkalingam, R., and Mahendran, M., 2010, Annealing effect on phase transformation in nano structured Ni-Mn-Ga ferromagnetic shape memory alloy, Phase Transitions, 83, 509-517

[15] Malla, A., Dapino, M., Lograsso, T. and Schlagel, D., 2003, Effect of composition on the magnetic and elastic properities of shape-memory NiMnGa, Proc. of SPIE., 5053, 147-158

[16] Richard, M., Feuchtwanger, J., Schlagel, D., Lograsso, T., Allen, S. M. and O'Handley R. C., 2006, Crystal structure and transformation behaviour of Ni-Mn-Ga martensites. Scripta Materialia, 54, 1797-1801

[17] Vallal Peruman, K., Mahendran, M., and Seenithurai, S., 2010, Effect of Mn concentration on the phase transformation in Ni-Mn-Ga single crystal, Physica B, 405, 1770-1774

[18] Yanwei Ma, Awaji, S., Watanabe, K., Matsumoto, M., and Kobayashi, N., 2000, X-ray diffraction study of the structural phase transition of Ni2MnGa alloys in high magnetic fields. Solid State Communications, 113, 671-676

[19] Rama Rao, N.V., Gopalan, R., Manivel Raja, M., Arout Chelvane, J., Majumdar, B., and Chandrasekaran, V., 2007, Magneto structural transformation studies in melt spun Ni-Mn-Ga, Scripta Materialia, 56, 405-408

[20] Singh, R.K., and Gopalan, R., 2008, Thermal, structural and magnetic characterization of $\mathrm{Ni}-\mathrm{Mn}-\mathrm{Ga}$ sheets fabricated by powder in tube roll bonding technique, Materials Science and Engineering B, 151, 199-204

[21] Wirth, S., Leithe-Jasper, A., Vasil'ev, A. N., and Coey, J. M. D., 1997, Structural and magnetic properties of $\mathrm{Ni2MnGa,}$ Journal of Magnetism and Magnetic Materials, 167, L7-L11

[22] Jin, X., Marioni, M., Bono, D., Allen, S.M., O’ Handley, R.C., and Hsu, T.Y., 2002, Empirical mapping of $\mathrm{Ni}-\mathrm{Mn}-\mathrm{Ga}$ properties with composition and valence electron concentration, Journal of Applied Physics, 91, 8222-8224

[23] Tanja Graf, Claudia Felser, and Parkin Stuart, S.P., 2011, Simple rules for understanding Huesler compounds, Progress in Solid State Chemistry, 39, 1-50

[24] Xuan, H.C., Ma, S.C., Cao, Q.Q., Wang D.H., and Du, Y.W., 2011, Martensitic transformation and magnetic properties in high-Mn content, $\mathrm{Mn}_{50} \mathrm{Ni}_{50-\mathrm{x}} \mathrm{In}_{\mathrm{x}}$ ferromagnetic shape memory alloys, Journal of Alloys and Compounds, 509, 5761-5764

[25] Singh, R.K., Shamsuddin, M., Gopalan, R., Mathur, R.P., and Chandrasekaran, V., 2008, Magnetic and structural transformation in off-stoichiometric NiMnGa alloys, Materials Science and Engineering A, 476, 195-200

[26] Babita Ingale, Gopalan, R, Rajasekhara, M., and Ramb, S., 2009, Studies on ordering temperature and martensite stabilization in $\mathrm{Ni}_{55} \mathrm{Mn}_{20-x} \mathrm{Ga}_{25+x}$ alloys, Journal of Alloys and Compounds, 475, 276-280

[27] Morawiec, H., Goryczka, T., Seguib, C., Gigla, M., and 
Szczeszek, P., 2008, Martensitic transformation in an inhomogeneous off-stoichiometric Ni-Mn-Ga alloy, Materials Science and Engineering A, 481-482, 288-292

[28] Kanomata, T., Yasuda, T., Sasaki, S., Nishihara, H., Kainuma, R., Ito, W., Oikawa. K., Ishida, K., Neumann. K.U., and Ziebeck, K.R.A., 2009, Magnetic properties on shapememory alloys $\mathrm{Ni}_{2} \mathrm{Mn}_{1+\mathrm{x}} \mathrm{In}_{1-\mathrm{x}}$, Journal of Magnetism and Magnetic Materials, 321, 773-776

[29] Satish Kumar, A., Ramudu, M., and Seshubai, V., 2011, Effect of selective substitution of $\mathrm{Co}$ for $\mathrm{Ni}$ or $\mathrm{Mn}$ on the superstructure and microstructural properties of $\mathrm{Ni}_{50} \mathrm{Mn}_{29} \mathrm{Ga}_{21}$, Journal of Alloys and Compounds, 509, 82158222
[30] Soderberg, O., Aaltio, I., Ge, Y., Heczko, O., and Hannula, S.P., 2008, Ni-Mn-Ga multifunctional compounds, Materials Science and Engineering A, 481-482, 80-85

[31] Annadurai, A., Nandakumar, A. K., Jayakumar, S., Kannan, M. D., Manivel Raja, M., Bysak, S., Gopalan, R., and Chandrasekaran, V., 2009, Composition, structure and magnetic properties of sputter deposited Ni-Mn-Ga ferromagnetic shape memory thinfilms, Journal of Magnetism and Magnetic Materials, 321, 630-634

[32] Scheerbaum, N., Kraus, R., Liu, J., Skrotzki, W., Schultz, L., and Gutfleisch, O., 2012, Reproducibility of martensitic transformation and phase constitution in $\mathrm{Ni}-\mathrm{Co}-\mathrm{Al}$, Intermetallics, 20, 55-62 